\title{
THE EFFECTS OF MODELING EXPERT COGNITIVE STRATEGIES DURING PROBLEM-BASED LEARNING
}

\author{
SUSAN PEDERSEN \\ Texas A\&M University \\ MIN LIU \\ The University of Texas at Austin
}

\begin{abstract}
While problem-based learning (PBL) is widely regarded as an effective instructional approach, research on it has largely been restricted to advanced and/or gifted learners. This study examined the potential of a hypermedia based expert tool to scaffold regular education sixth graders engaged in a problem-based learning (PBL) program. Participants completed Alien Rescue, a hypermedia PBL environment on the solar system. The tool under investigation offered students interactive video of an expert modeling his cognitive processes as he performed tasks relevant to the development of a solution to the central problem of the PBL unit. Two other versions of the expert tool were developed to isolate the effect of the cognitive modeling. Results suggest that the cognitive modeling offered through the expert tool brought the way students worked during periods of self-directed study into line with expert actions and impacted the quality of the rationales students wrote for their solutions.
\end{abstract}

\section{INTRODUCTION}

The recent shift within the field of instructional technology to design based on a constructivist framework has led to a renewed interest in problem-based learning (PBL), with Savery and Duffy going so far as to argue that PBL is the instructional approach that best realizes the tenets of constructivism [1]. In PBL, learning 
occurs as a result of students' efforts to solve a complex problem. Instruction begins with the presentation of a problem situation, and in order to develop a solution, students identify learning needs, locate resources to meet those needs, and apply their learning to the problem situation. Proponents of PBL have expounded on its many potential benefits, among them improved self-directed learning [2,3], development of problem-solving skills [4], and a positive attitude toward learning through this approach [5].

While PBL offers many possible benefits, there are several difficulties with this approach that may complicate its general use in K-12 settings. Much of the research on PBL has focused on gifted and mature learners, making it difficult to extrapolate these findings to a wide range of learners. Hmelo and Ferrari even suggest that PBL is more suitable for use with the gifted than with regular education students because the former possess more sophisticated learning strategies, and are more reflective and intrinsically motivated than their regular education peers [6]. However, the benefits of PBL represent valuable educational goals for all learners, not just for the gifted. An examination of the potential difficulties average learners may encounter during PBL can lead to the development of supports that could make this approach viable in more classrooms.

Self-directed study poses one such difficulty. Extensive periods of self-directed study are a fundamental feature of PBL; students must determine what information they need, what resources to use to gather it, how to organize it, and the sequence in which to perform the assorted tasks necessary to solve the problem. Learners are typically allowed to pursue blind alleys in their problem-solving efforts without interference on the part of the teacher [4]. Even in medical programs, learners initially have difficulty with the lack of externally imposed structure and responsibility for self-directed study [3]. Young learners of average ability may lack the skills to identify pertinent learning needs and the resources that can meet them. They may have less developed planning skills and be less able to reflect upon their efforts and change them when necessary. Supporting students' self-directed study during PBL is complicated by the fact that students' activities are context specific. The activities that occur during self-directed study vary from problem to problem, as students gather and interpret information in ways particular to a given problem situation.

Classroom teachers can provide some support, but PBL may place overwhelming demands on the teacher's time. The role of the teacher differs dramatically in a PBL class from that of the traditional classroom, where the teacher determines the content and sequence of the objectives to be met and provides direct instruction. During PBL, the role of the classroom teacher is generally regarded as that of a facilitator, helping learning to occur, but controlling neither its content nor its process. Depending on the abilities, maturity, and needs of the learners, facilitators typically probe students' comprehension in order to diagnose misconceptions and identify knowledge deficiencies, monitor group processes to insure helpful interactions and participation by all learners [7], 
provide metacognitive coaching to help students to examine their thinking and internalize the habit of questioning $[3,8]$, and make moment to moment decisions about how to best facilitate the PBL process in order to meet the idiosyncratic needs of individual students and classes [6].

As important as what the teacher does is what the teacher does not do. PBL is designed to be student-centered; a teacher who is overly directive can deny students the opportunity to reason and engage in self-directed study, thus undermining major goals of the PBL approach. On the other hand, a teacher who is too passive will fail to guide students to consider all the steps in the reasoning process and develop the habit of questioning. Students will flounder, making the PBL experience less productive and enjoyable than it should be. Barrows cautions that the skillfulness of the teacher has a major impact on the success of PBL [9]. The potential of PBL to promote students' development of problem-solving and self-directed learning skills is dependent on both a student-centered approach and sufficient support. This tightrope may be too narrow for teachers inexperienced with PBL.

The difficulty of this balancing act is exacerbated by the lack of self-directed study skills on the part of young, average learners, which may tempt teachers to "take charge," falling back on the traditional instructional patterns of teachercentered education. As a result the teacher may unwittingly sabotage the opportunity PBL offers to make learning student-centered and help students develop skills of self-directed study. In this light, PBL may become a viable approach for more K-12 classrooms if PBL instructional materials incorporate support for students' work during self-directed study. Not only can these materials share with the teacher the responsibility for delivering the many types of support learners need, they can also be fine tuned to be as non-directive as possible. This can relieve the teacher of one of the more subtle and complicated types of support students may need, leaving him or her to focus on needs particular to his or her students.

\section{COGNITIVE APPRENTICESHIP SUPPORT FOR PROBLEM-BASED LEARNING}

In her critique of PBL, Williams concluded that a weakness of this approach is that, in the absence of good models of problem solving, students must acquire skills through trial and error [3]. As a result, novices sometimes flounder, adopt ineffective strategies that interfere with later learning, and experience frustration. She recommended that learners be given the opportunity to see experts in action, using domain knowledge and strategies to solve problems. The type of support she advocates constitutes a cognitive apprenticeship, wherein learners work with experts within a domain, gradually becoming aware of and internalizing the cognitive processes of those experts [10]. In a cognitive apprenticeship, the internal processes that normally remain hidden are externalized. As both experts and novices work together on a task, they can observe and compare their thinking 
in order to help the novice develop and apply the same knowledge and skills as the expert.

To be effective, experts must provide just the level of support needed by the novice to perform the task; like the narrow balance required of the PBL facilitator, either too much or too little support may limit the apprentice's opportunity to participate effectively in the community. Drawing on the work of A. L. Brown [11], Derry and Lesgold propose a three-stage model in which the role of the expert mentor changes as the learner progresses toward proficient participation [12]. In the first stage, the expert models his or her problem-solving, thinking aloud so that the apprentice has the opportunity to see what cognitive and metacognitive strategies the expert brings to bear on a task. In stage two, the expert and apprentice work together, with the expert modeling, coaching, and prompting only as the apprentice falters or requests support. In stage three, the apprentice is given control of the task, and the expert's support is limited to that of questioning and serving as a supportive audience. Learners new to a domain or who possess limited problem-solving and self-directed study skills would fall in the first stage of this model. This suggests that, for these learners, modeling of the cognitive and metacognitive processes an expert brings to bear in addressing the task posed by the PBL environment may be an appropriate support.

Modeling is a teaching method wherein the learner is given an opportunity to observe the internal cognitive processes of an expert as he or she problem-solves [10]. Usually this is done by having the expert do "think alouds" as he or she deals with a problem or by sharing stories of the thinking processes he or she has used to solve problems in the past. This externalization of these normally internal cognitive events allows students to see how an expert uses domain specific knowledge and a range of problem-solving strategies to perform tasks within a given context. This helps students to develop conceptual models of the processes that are required to accomplish the task. Through the provision of modeling during PBL, learners may work more effectively and experience less frustration.

\section{USING HYPERMEDIA TO OFFER EXPERT MODELING}

Hypermedia programs are characterized by a coordinated use of multiple media and interactivity and differ from multimedia programs in the level of control they offer users over navigation and sequence. These features mean that hypermedia programs offer a number of affordances that make them an effective medium through which to deliver and support PBL. For example, the non-linear access to information afforded by hypermedia means that a program can contain all information needed to solve a problem without suggesting a sequence of learning within the PBL unit. The multiple media allow a degree of realism and richness in the presentation of a problem scenario. The study reported here describes and 
examines a tool that capitalizes on the affordances of hypermedia to offer cognitive apprenticeship support to learners engaged in PBL.

Through the use of audio, video, animation, and context-sensitive timing, a hypermedia program can be designed to offer modeling of pertinent strategies as students are engaged in problem-solving by providing expert opinions at appropriate points throughout the program. These "experts" can be hypermediabased characters who pop up at key points within the program to share relevant stories or explain useful strategies, as in the case of this study. While the classroom teacher could also model his or her cognitive processes for the class, presentation of this modeling through hypermedia may have some distinct advantages. First, hypermedia delivered modeling of expert processes can be offered in a "just-in-time" manner. The modeling can be time or location sensitive; it can be offered after students have spent a certain amount of time in the program, or only when they are using certain tools within the program. Second, delivery of the modeling can be under program or user control, depending on design considerations. In other words, the instructional designer can determine that some modeling is essential, and design the program so the students are channeled into viewing it at certain points, without the option of bypassing it. On the other hand, it is possible to leave control over access to the learner, allowing him or her to view the modeling only if and when he or she believes the expert modeling would be helpful. Third, hypermedia is endlessly patient. Students can review the expert's cognitive processes as many times as they like, controlling which parts they replay. Finally, the hypermedia delivered modeling can be developed by a team of instructional designers, meaning that it can draw on the expertise of several educators rather than a single classroom teacher. The teacher, whose experience with the program may be limited, may not yet possess the expertise in addressing the problem situation required for helpful modeling. The teacher may lack the skill of making his or her own cognitive processes explicit, focusing on what he or she does instead of why those choices are useful. He or she may also be tempted to become overly directive, telling students to perform tasks in a particular sequence and only in the manner modeled. The hypermedia based support can be carefully designed to avoid authoritative language that may limit students' sense of control over their process.

Though Collins argued a decade ago that hypermedia could be used to offer cognitive apprenticeship style support, thus realizing types of learning environments that have not been possible or cost-effective in the past, limited attempts have been made to utilize the affordances of hypermedia in this manner [13]. A major line of research on using hypermedia to provide cognitive apprenticeship support focuses on intelligent tutoring systems (ITSs). While ITSs come in a variety of flavors, their primary goal is typically to provide coaching, a type of cognitive apprenticeship support in which the teacher (in this case the computer) watches learners as they are engaged in a given task, then gives hints and feedback which are designed to improve their performance. The drawback to ITSs is that 
they are time-consuming and expensive to develop [14] because of the complexity of identifying and developing responses to the many possible actions learners can take. Alternative ways of exploiting hypermedia to provide cognitive apprenticeship support is warranted.

\section{THE PURPOSE OF THE STUDY}

Two concerns were raised in the review of literature. First, despite the evidence of the benefits of problem-based learning, its use has largely been restricted to mature and/or gifted learners, offering limited challenge to the perception that PBL is not a suitable approach for young students or regular education classrooms. Second, the self-directed study component of PBL can be difficult for young learners, and the support they need to develop the necessary skills for self-directed study can place an overwhelming burden on a classroom teacher. This study seeks to determine if a hypermedia based tool can share the responsibility for supporting learners during PBL, making this approach a viable and beneficial option for middle school students in regular education classes. This tool offers video-based modeling of an expert's cognitive processes as he engages in the same activities that are useful to students participating in a PBL program, and its design was informed by the literature on cognitive apprenticeship.

This expert tool has two functions. First, it is designed to give learners ideas about useful activities to engage in during the periods of self-directed study that form an important part of the PBL process. Learners who are inexperienced with self-directed study may lack the skills to put this time to good use, and may even flounder, unable to determine how to get started or what to do if they get stuck. By modeling the activity of an expert, this tool is designed to help learners use periods of self-directed study effectively. Second, the expert models a variety of skills useful in problem-solving, such as reading to gather pertinent information, making connections between pieces of information, recording information for later use, forming hypotheses, asking questions, developing a plan to collect data, and supporting a solution plan with a rationale. As learners view the video segments provided in the expert tool, they can see how an expert would apply these problem-solving skills to the same task that they face. This study therefore sought to determine whether or not the expert tool impacted the way learners worked during periods of self-directed study, and if so, whether or not this support resulted in more well reasoned rationales for the solutions learners developed for the problem presented in a PBL unit.

Additionally, a potential negative effect of the expert tool was investigated. As explained above, PBL is designed to be student-centered; the introduction of a scaffold like the expert tool may interfere with students' sense of ownership over their process, which could negatively impact both their attitude toward the environment and their interest in participating in similar ones. Therefore, the effect of the expert tool on learner attitude was examined. The purpose of including this 
examination was to determine whether or not a tool designed to benefit selfdirected study and problem-solving might also have a drawback, namely a detriment to student attitude.

\section{DESIGN}

\section{Research Questions}

The research questions for this study focus on the effects of expert cognitive modeling on learners' performance within and attitudes toward the learning environment:

- Does hypermedia-based expert modeling affect learners' work during periods of self-directed study in PBL?

- Does hypermedia-based expert modeling affect the quality of the rationale students develop for their solution to the central problem posed by the PBL unit?

- Does hypermedia-based expert modeling affect learners' attitude toward a PBL environment?

\section{Sample}

Sixty-six students in three intact sixth grade science classes at a suburban middle school in the southwestern United States participated in the study. These three classes were taught by the same teacher. Classes were randomly assigned to the treatment conditions. There were 20 students in the class assigned to the modeling condition, 22 students in the class assigned to the didactic condition, and 24 students in the class assigned to the help condition.

The ethnic makeup of the classes reflected the school at large. Seventy-seven percent of the participants were Caucasian, 15 percent were Hispanic, 5 percent were African American, and 3 percent were Asian. The classes were split almost evenly by gender, with two more girls than boys participating in the study.

\section{Instructional Materials}

The hypermedia program used in this study was Alien Rescue, a problem-based learning environment for use in sixth grade science classes. The science fiction premise of this program places students in the role of young scientists aboard a newly operational international space station where they are part of a worldwide effort to rescue alien life forms. The opening scenario of Alien Rescue informs students that an alien ship has entered Earth orbit and sent a distress message explaining that the aliens aboard the ship are the survivors of a distant solar system that was destroyed by the explosion of a nearby star. An accident during their voyage has left their computer damaged and the aliens are in suspended animation 
because their ship can no longer provide life support. Students are assigned the task of recommending worlds in our solar system that would be suitable homes for each of the six species of aliens aboard the ship. To accomplish this goal, students learn about the planets and large moons of our solar system by searching existing databases and using a simulation within the program that allows them to design and launch probes and interpret the data these simulated probes collect. While the primary learning objectives of Alien Rescue focus on astronomy and space travel, the program offers ties to other areas of the curriculum, including life science and mathematics. The program provides several opportunities for writing: students record notes in an online notebook, develop mission statements for the probes they design, and write rationales for the solutions they develop.

The focus of this study is on one tool provided within the Alien Rescue environment: the expert tool. This tool offers video segments of a character who is an expert scientist engaged in the same task as learners, that of finding homes for the aliens. The purpose of this tool is to show learners strategies that an expert would use while addressing this problem. It is designed to provide just-in-time support as learners are engaged in various tasks so as to make their periods of self-directed study more productive and help them to develop better solutions to the problem.

\section{Treatment Conditions}

Three versions of expert support were used as the treatment variable. In the modeling condition, an expert modeled two general tasks: his cognitive processes during problem-solving activities and tool functionality. In the didactic condition, the same expert explained tool functionality and offered tips on how learners should work during self-directed study, but did not model his application of these strategies to the tasks at hand. In the help condition, the expert explained tool functionality outside of the context of their use in problem-solving activities but did not offer any advice about how students should work. By comparing these three conditions, it is possible to isolate the effect of the cognitive modeling on learners' self-directed study and problem solving.

\section{The Modeling Condition}

In the modeling condition, an expert modeled his cognitive processes as he engaged in problem-solving activities within the Alien Rescue environment. These activities are ones that occurred as students were engaged in self-directed study. This modeling was delivered in video format within the hypermedia program, "just-in-time" to students as they were working within the section of the program where the modeling was useful. The expert modeled his thinking as he developed a solution for one of the alien species; students were expected to work on the other five species. 
The key tasks an expert would perform in working toward a solution were identified, and a modeling session was developed for each of the tools he or she would use while performing that task. Altogether there were four modeling sessions, all of which students were expected to watch in the course of their work in the program. In each modeling session the expert "thought aloud" about the problem, explaining what he was trying to accomplish and how he used the tools within the program to conduct his work. The expert modeled numerous strategies, including self-questioning, making connections, identifying missing information, forming and recording hypotheses, and taking notes in a list format (rather than writing notes in complete paragraphs).

\section{The Didactic Condition}

The didactic condition was designed to provide students with all of the same information provided in the modeling condition, but without expert modeling. Video segments of the expert popped up at the same four points in the program in this treatment condition as in the modeling condition. The expert explained tool functionality, then offered learners tips about how to work effectively. The content of these tips was determined by examining the modeling sessions to identify the strategies that were modeled. Each of these strategies was then listed as a short sentence, and an explanation for it was developed.

As the expert presented each tip, he offered an explanation that tied it to the task at hand, and the tip appeared on the screen. For example, when the expert offered the tip "Ask yourself questions," he explained that learners may want to stop and ask themselves "Does this tell me something that the species needs to survive?" The expert did not actually apply the strategy to the task, and did not model his thinking as he engaged in the problem.

The purpose of including this condition was to isolate the effects of the modeling from the effects of the simple provision of helpful strategies. Because both conditions presented the same strategies and explained their usefulness, it is possible to determine if simply cueing students to use certain strategies impacts their performance to the same degree as expert modeling of these strategies. A difference in outcomes between these two condition groups could not be attributed to a difference in amount of support offered; it could only be attributed to the method used in presenting that support.

\section{The Help Condition}

In the help condition, the expert explained the functionality of the tools provided in the program as students accessed them. As in the other conditions, there were four help sessions. These four help sessions contained the same information about tool functionality offered in the previous two conditions, but the expert provided no advice on how students should work. 
The content of these help sessions was developed by examining what information learners in the modeling condition were given about the functionality of each of the tools used during the session. The help condition was designed to reflect the typical type of help provided in a software program; such help supports learners in the efficient use of a tool without suggesting the reasons they should use the tool or the cognitive processes that would make for effective problem-solving. Providing this content to students in one condition made it possible to isolate the effects of the introduction of problem-solving strategies from the effects of support for understanding tool functionality.

A comparison of the three treatment conditions is shown in Table 1.

\section{Dependent Variables}

Three dependent variables were examined for the effects of the expert tool: learners' actions within the program during periods of self-directed study, their rationale for the solutions they offered to the central problem of the PBL unit, and their attitude toward the program and the expert.

\section{Self-Directed Study}

Extensive periods of self-directed study are an integral element of problembased learning. The expert tool in Alien Rescue is designed to impact the way students work during self-directed study. The program features an extensive audit trail that keeps track of the actions learners take and the artifacts they construct. This audit trail was examined in depth to determine whether the expert tool had any effect on how students used two other tools in the program: their online notebooks and the mission statements for the probes they designed. These tools were examined both for how often students accessed them and for the contents of the statements students recorded in them.

To identify the types of differences that could be expected, the scripts for the expert modeling segments were examined and a list of modeled behaviors that would leave a trail in learners' work was generated. Differences in the way learners performed these tasks would support the claim that the hypermedia based expert modeling affected learners' actions during self-directed study. Ten measures were used to examine learners' actions during self-directed study:

- Number of parsed statements included in the notebook by the seventh day. By this point in the program, students had had the opportunity to hear at least the first two expert sessions, each of which contained support for the use of the notebook. The contents of students' notes were parsed into statements that each contained a single fact or concept. For example, the sentence "The Jakala-Tay have long tails and breathe sulfur" would be parsed into two statements: "The Jakala-Tay have long tails" and "The Jakala-Tay breathe sulfur." Students' score was the total number of statements recorded. This was 
Table 1. Comparison of the Three Treatments on One Strategy: Writing a Probe Mission Statement

\begin{tabular}{lll}
\hline Condition & \multicolumn{1}{c}{ Description } & \multicolumn{1}{c}{ Example: Text of expert script } \\
\hline Modeling & $\begin{array}{l}\text { The expert introduces a } \\
\text { strategy then models } \\
\text { applying it to the current } \\
\text { task. As he does so, he } \\
\text { actually uses the tool, } \\
\text { so learners see how the }\end{array}$ & $\begin{array}{l}\text { This next part is the most important part: } \\
\text { writing your mission. Probes are very } \\
\text { expensive. We have to have a pretty good } \\
\text { reason to spend that much money. In other } \\
\text { words, we need to make sure our probe is }\end{array}$ \\
going to answer our most important questions.
\end{tabular}
tool functions.

Figuring out what questions we need to have the probe answer is kinda tough, so l'm going to show you how I do it. First, I'm going to think about what the Eolani need. ...

The session continues with the expert modeling the development of questions. He then designs a probe that includes the instruments needed to gather data to answer the questions he developed.

Didactic The expert explains how the tool functions, then later suggests that students use a particular strategy as they work. He explains the value of this strategy and may offer an example to further illustrate it, but does not actually apply it to the current task.

This is the Probe Info box. Here you fill in a name for your probe, its mission, and its destination. When you're done, click OK to close this box and start designing your probe.

Any time that you want to see this box again, just click on the probe info button.

Later in the session, the expert explains the same problem-solving strategy modeled in the modeling condition:

Finally, if I were building a probe, I would use my mission statement to help me decide what to include on my probe. Since the mission statement lists all the questions I want to try to answer, I can use it to make sure I choose the instruments that will collect the data I need. For example, if I have a question about temperature, I would want to be sure to include an instrument that measures temperature. By opening up my probe info box, I can review the mission for the probe and make sure all my questions will be answered.

Help The expert explains how the tool functions, but does not offer any suggestions about This is the Probe Info box. Here you fill in a name for your probe, its mission, and its destination. When you're done, click OK to close this box and start designing your probe.

Any time that you want to see this box again, just click on the probe info button. 
used to determine if the treatment condition impacted the number of notes taken. Scores for this measure ranged from 0 to 67.

- Number of statements in the notebook that were relevant to the solution development by the seventh day of class. Relevant facts were defined as those that could help the learner to match the needs of alien species to the characteristics of worlds in our solar system. For example, the note "Io has a thin atmosphere" was scored as relevant because several species need atmospheres. In contrast the note "Io wobbles a little in its orbit of Jupiter" was scored as irrelevant; while interesting, this fact is not related to the needs of any of the species, and could not help learners to determine if any of the species might be able to live there. The learner's score on this measure was the total number of relevant statements he or she recorded, and was used to examine the impact of the treatment condition on learners' ability to identify pieces of information useful to the development of a solution. Scores on this measure ranged from 0 to 49 .

- Percentage of statements in notebooks that were relevant to the solution development by the seventh day of class. This figure was calculated by dividing the number of relevant statements by the total number of statements students recorded. The purpose of this score was to collapse the above two measures into a single variable that would reflect the degree to which students were able to distinguish pieces of information useful for development of a solution from other facts that were not helpful. A high percentage score indicated that a student, no matter how many facts he or she recorded, seemed to understand which facts would be useful in solving the problem. A low score, on the other hand, indicated that the student tended to record a variety of facts without attention to which ones were of use in developing a solution. Because ten of the students had not recorded any notes, they did not receive scores for this measure; therefore, for this measure only, $N=56$. Only one of the students in the modeling condition did not record notes; the figures for the didactic and help groups were 7 and 2 respectively.

- Use of lists in the notebook by the seventh day of study. The program designers and subject matter experts who developed the software used in this study identified this as a useful strategy because items in a list tend to be more succinct than complete sentences, and because lists facilitate later review of information better than the same information recorded in paragraph form. Students'use of lists were scored on a zero to three-point scale, and this measure was used to indicate how the expert impacted the way they use tools.

- Number of meaningful sections created in the notebook. Again, program designers and subject matter-experts who developed this software program considered organizing notes into sections an expert strategy because it helps the learner to structure information in a meaningful way and makes those notes more readily accessible for later review. A section was considered meaningful if it had a title of a species, a world, or a relevant science topic, 
plus at least ten words of notes, or if it had more than thirty words of notes related to one of these topics. Students' score on this measure equaled their total number of sections, and the scores were used to examine the effect of the expert on students' tool use. Scores on this measure ranged from 0 to 11 .

- Number of times notebook was accessed. The expert modeled opening and closing the notebook frequently, so as to move flexibly between the notebook and the tool it covers. This is considered an expert skill because it indicates flexible and coordinated use of tools. The program audit trail provided a count of the total number of times students opened their notebooks. Students' score on this measure was equal to the number of times they opened their notebooks, and was used to examine the effect of the expert on students' tool use. The range of scores for this measure was 7 to 134 .

- Number of probes designed. The expert modeled recording questions in the probe mission statement that reflect the information about a world that is missing from the solar system database but that is relevant to the solution development. He further modeled selecting instruments for the probe based on the questions recorded in the probe mission statement. While the expert did not suggest that students should limit the number of probes they design, one expected effect of this modeling was that students in the modeling condition would be more planful in their design efforts than students in the other conditions. Since this is time-consuming, students in the modeling condition would be expected to design fewer probes. The number of probes students designed during the entire course of the program was counted and this number served as their score on this measure. Students' scores on this measure ranged from 1 to 50.

- Percent of probes designed that had meaningful mission statements. A meaningful mission statement is one that identifies specific pieces of data that the probe should collect. Mission statements that include questions like "Does Titan have a magnetic field?" or statements like "check for oxygen in atmosphere" are considered meaningful. Mission statements that contain vague statements such as "see if the Wroft can live there" or where the content is gibberish or missing altogether are not considered meaningful. The expert modeled writing meaningful probe mission statements in the third modeling segment. The number of probes containing meaningful mission statements were divided by the total number of probes the learner designed to derive a percent score for this measure. Scores on this measure ranged from 0 to 13.

- Number of times probe mission statement was accessed. The expert modeled referring back to the probe mission statement to guide the probe design process. This is considered an expert strategy in that the learner works to the specifications he or she developed in the mission statement. The program audit trail recorded the number of times students accessed the mission statement, and the total served as a score on this measure. This was used to examine the effect of the expert on students' tool use. Students' scores on this measure ranged from 0 to 41 . 


\section{Problem Solution and Rationale}

A form is provided within the Alien Rescue environment for students to enter their recommendations for the problem solution for each of the six species. This form contains six sections, one for each species. Each section has two parts: a drop down menu students use to select a world for the species, and a text field where they type a rationale for their decision. Use of this form is modeled by the hypermedia-based expert. In class, students shared the responsibility for developing rationales for each of the species, with each individual student responsible for writing rationales for their recommendations for new home worlds for two of the species.

Students' recommendations for each of these two species were evaluated separately using a rubric, then the scores for each were totaled. The criteria included in the rubric are explained below.

- Correctness of the proposed solution: zero to two points. For each species, there are one or two "best" choices, and one or two other "acceptable" choices. Students received two points if they recommended a best choice, one point if they recommended an acceptable choice, and zero points for any other choices.

- Inclusion of a topic sentence: zero to one point. Essays that included a topic sentence scored one point and essays that lacked them scored zero.

- Number of supporting details: zero to six points. Students scored one point for each supporting detail that they offered, to a maximum of six points. Details in excess of six did not score additional points so as to prevent the inclusion of supporting details from overwhelming the other aspects of the task. The large point value for this criterion was deemed appropriate by the raters because much of the modeling provided by the expert was aimed at including appropriate supporting details in the rationale and because the effectiveness of a rationale for a decision is largely dependent on the number of specific supporting details offered.

- Inclusion of potentials drawbacks: zero to one point. If the student acknowledged that a world may have one or more drawbacks, one point was scored. Failure to mention potential drawbacks scored zero points.

- Overall persuasiveness of rationale: zero to two points. This was the most subjective part of the rubric and gave the raters the opportunity to evaluate the solution and rationale holistically. Through discussion and group scoring of some of the essays, the raters identified some characteristics of persuasive responses. The raters agreed that persuasive responses do not contain irrelevant statements, make ties between the needs of the species and the selected world, do not use vague supporting details, and generally have nothing that detracts from the purpose of the essay. While the number of supporting details included affects the overall degree of persuasiveness of an essay, the raters 
made every attempt to focus on other strengths and weaknesses of the essay in order to determine the score for this item in the rubric.

Scores for each of the recommendations ranged from a minimum of zero points to a maximum of 12 points; by totaling the scores on the two recommendations each student wrote, scores for each student ranged from zero to 24 points for this measure. Two raters, one of whom was blind to the students' treatment conditions, scored students' recommendation essays. An orientation was held in which the raters discussed how to score the essays, and the raters scored 10 percent of the responses together. Raters scored the remaining responses independently, then exchanged responses and reviewed the scoring. Discrepancies were discussed until agreement was reached on all of them, resulting in an interrater reliability of 100 percent.

\section{Attitude toward the Learning Environment}

Students' attitude toward the Alien Rescue environment was examined using the Attitude toward Learning Environment questionnaire, which was administered in the final week of the study. This 19 item questionnaire uses a 5-point Likert scale with responses ranging from 1 for Disagree Strongly to 5 for Agree Strongly. Four subscales are included. These subscales are shown in Table 2 with related reliability information.

There have been several phases in the construction of The Attitude toward Learning Environment questionnaire, each of which has resulted in changes. It is based on a questionnaire originally developed by S. Williams to assess attitude toward a mathematics software environment [15]. In the next phase it was modified by D. Williams to assess attitude toward the Alien Rescue environment [16]. The scale was further modified to assess attitude toward the expert modeling within the Alien Rescue environment as well as toward the environment as a whole. This version was pilot tested, changes were made based on a reliability

Table 2. Reliability of Subscales in the Attitude toward Environment Questionnaire

\begin{tabular}{lccc}
\hline Subscale & $\begin{array}{c}\text { Number of } \\
\text { items in } \\
\text { subscale }\end{array}$ & $\begin{array}{c}\text { Reliability } \\
\text { scores from } \\
\text { pilot test after } \\
\text { modifications }\end{array}$ & $\begin{array}{c}\text { Reliability } \\
\text { scores from } \\
\text { current sample }\end{array}$ \\
\hline Helpfulness of expert & 5 & .89 & .90 \\
Enjoyment of expert & 5 & .79 & .86 \\
Enjoyment of alien rescue & 4 & .83 & .77 \\
Educational value of alien rescue & 5 & .77 & .70 \\
\hline
\end{tabular}


analysis of each of the subscales, and this revised version was used in this study. A copy of the questionnaire is included in the Appendix.

\section{Procedures}

The study was conducted during students' regular science class times, which were daily 45 -minute periods. Students were engaged in the program for approximately 15 class periods.

Each student worked at his or her own computer. Students were encouraged to work together to share the information they discovered and to ask each other for help. They were not, however, assigned partners or told they had to divide up the work in any way.

The researcher served as the teacher during the study. In this role, she led whole class discussions, encouraged peer interactions, questioned students about their probe designs and provided funding for students to launch the probes, and did troubleshooting on technical problems. The regular classroom teacher remained in the computer lab with her classes.

On the first day of the study, learners watched the opening scenario of Alien Rescue then began exploring the environment on their own. Over the following two and a half weeks students engaged in self-directed study, spontaneous collaboration, and whole class discussions. Whole class discussions occurred at the beginning of most classes and tended to last between 8 and 15 minutes. During these discussions the learners shared information they had discovered, asked questions of their classmates to find needed information, discussed scientific topics, and modeled their problem-solving process for their peers. The remainder of the time each day was spent with students working at their computers in a self-directed manner. Many of the students collaborated, sharing information and sometimes dividing up responsibility for finding information. Students were asked to listen to the expert and were told that they would be asked at the end of the study to share their opinions of the expert. The attitude questionnaire was administered in the last week of the study.

\section{Data Analysis}

To answer the first question, "Does hypermedia based expert modeling affect learners' work during periods of self-directed study in PBL?" a one-way ANOVA was calculated for nine of the ten measures described in the section on selfdirected study, with treatment condition assignment as the between groups variable. For the remaining measure, The Use of Lists in the Notebook, the data showed a non-normal distribution; therefore a Kruskal-Wallis Test was used. To control for a Type 1 error, the Bonferroni adjustment was made and the adjusted alpha level was set at .005 (.05/10). Eta-squared was calculated to determine the overall effect size for each of the ten measures. Cohen's $d$ was then calculated to assess the effect size for each of the pairwise comparisons. 
For the second question, "Does hypermedia based expert modeling affect the quality of the rationale students develop for their solution to the central problem posed by the PBL unit?" learners' scores on the problem-solving solution and rationale measure were analyzed with a one-way ANOVA, with treatment condition as the between groups variable.

The third research question, "Does hyperrnedia based cognitive modeling affect learners' attitude toward the learning environment?" was addressed using students' responses to The Attitude toward Environment questionnaire. A series of analysis of variance tests was conducted to determine if students differed by treatment condition on any of the subscales.

\section{RESULTS}

\section{Self-Directed Study}

The analyses of variance of the self-directed study measures showed an overall significant difference among the treatment condition groups in five of the ten measures. Post hoc analyses were conducted on these five measures using Tukey's HSD. Table 3 summarizes the differences among the three treatment groups.

These results suggest that the treatment condition affected students' work during self-directed study in a number of ways. First, they show that the expert modeling impacted the way students used the notebook. Students in the modeling condition showed greater organization of their notes than students in the other conditions, recording them in list format and separating them into sections by topic. They also used the notebook more flexibly, opening and closing it more often than their peers in order to coordinate its use with the use of other tools. Students in the modeling group also tended to record more notes that were relevant to the solution. While this measure fell short of statistical significance $(p=.007$ where the alpha level was set at .005), Cohen's $d$ for the pairwise comparison of the modeling and didactic groups shows a relatively large effect size $(d=1.01)$. This suggests that students in the modeling condition were better able to focus on information relevant to solving the problem than their peers in the didactic condition.

Interestingly, the results also show differences between the didactic and help groups in how they used the notebook that were not predicted in the study. Students in the help group were significantly more likely to record their notes in list format, and though the difference was not statistically significant, they also recorded more notes than did the didactic group.

Evidence of the effect of the modeling can also be seen in students' work on probe design. As predicted, students in the modeling condition designed significantly fewer probes $(p<.01)$, suggesting they spent more time developing each probe. Even though they designed far fewer probes, they developed a greater number of meaningful mission statements, and this difference is particularly 
370 / PEDERSEN AND LIU

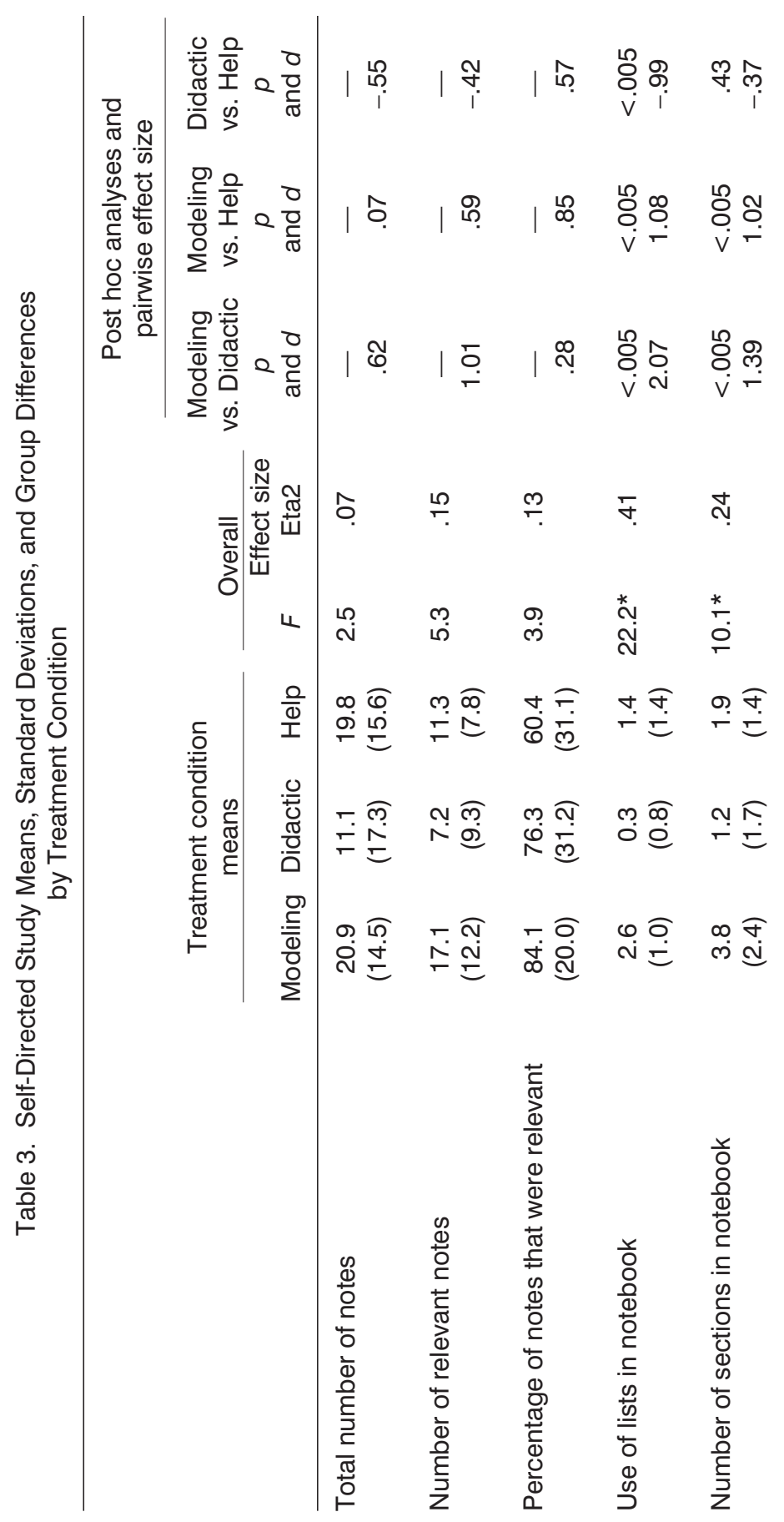




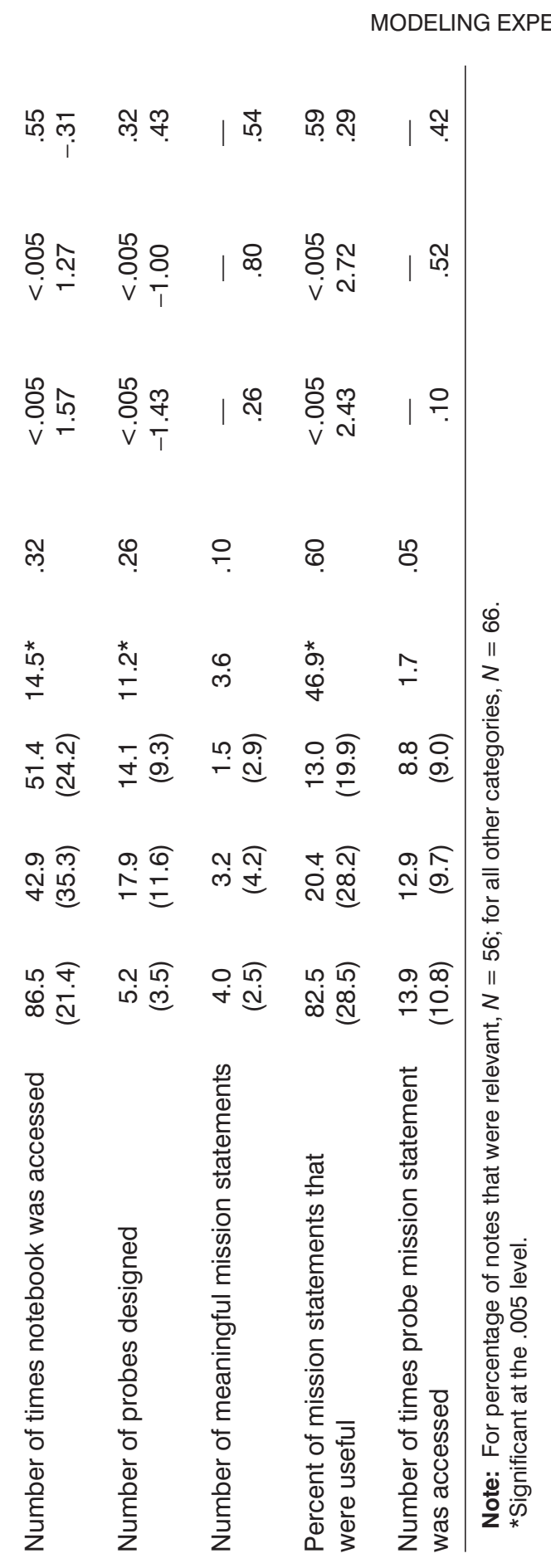


striking when viewed as percentages. Students in the modeling condition wrote useful mission statements for 82.5 percent of their probes, while students in the didactic and help conditions wrote useful mission statements for 20.4 percent and 13 percent of their probes respectively. There was no significant difference in the number of times students accessed their probe mission statements, but this figure may be deceptive. Considering that students in the modeling condition designed far fewer probes, they still accessed the mission statement more often than their peers, suggesting that they used the probe mission statement as the expert recommended: as a guide for their selection of instruments to include on the probes. Taken together, these results suggest that students in the modeling condition worked in a far more planfid manner than students in the other conditions.

\section{Problem Solution and Rationale}

Mean scores on students' solutions to the problem posed in Alien Rescue were 14.1, 7.3, and 7.0 respectively for the modeling, didactic, and help groups. The results of the analysis of variance revealed a significant difference on this measure $(F=20.13, p<.01)$. Post hoc analysis using Tukey's HSD showed that the modeling group performed significantly better on this task than both the didactic group $(p<.01)$ and the help group $(p<.01)$. There was no significant difference between the didactic and help groups. In addition to statistical significance, the effect size was quite large (Cohen's $d=1.66$ for the modeling vs. didactic groups and 1.73 for the modeling versus help groups), suggesting that the modeling condition had practical significance as well.

\section{Attitude toward the Learning Environment}

Results of the analysis of variance conducted on the students' responses to the Attitude toward the Learning Environment questionnaire showed differences between the modeling condition and the other two groups on two of the subscales (see Table 4). Contrary to concerns raised in the review of literature, students in the modeling condition liked the expert better than students in the other conditions. Post hoc tests showed that the difference between the modeling and didactic groups was significant $(p<.05)$. Students in the modeling condition also found the expert more helpful than students in the other two conditions, and this time post hoc analysis showed that the difference between both the modeling and the didactic groups and the modeling and help groups was significant at $p=.01$. Overall these results suggest that students in the modeling group had a more positive attitude toward the expert than students in the other treatment conditions. 
Table 4. Means, Standard Deviations (in Parentheses) and Analysis of Variance for Subscales of the Attitude toward the Learning Environment Questionnaire

\begin{tabular}{lccccc}
\hline Subscale & $\begin{array}{c}\text { Modeling } \\
\text { condition }\end{array}$ & $\begin{array}{c}\text { Didactic } \\
\text { condition }\end{array}$ & $\begin{array}{c}\text { Help } \\
\text { condition }\end{array}$ & $F$ & $\begin{array}{c}\text { Effect } \\
\text { size }\end{array}$ \\
\hline Enjoyment of expert & $\begin{array}{c}3.4 \\
(.85)\end{array}$ & $\begin{array}{c}2.7 \\
(.82)\end{array}$ & $\begin{array}{c}3.0 \\
(.81)\end{array}$ & $4.18^{*}$ & .12 \\
& 4.0 & 2.6 & 3.1 & $11.56^{\star *}$ & .27 \\
Helpfulness of expert & $(.83)$ & $(1.04)$ & $(.81)$ & & \\
& 3.9 & 4.3 & 4.2 & 2.30 & .07 \\
Enjoyment of & $(.87)$ & $(.56)$ & $(.52)$ & & \\
Alien Rescue & 3.9 & 4.2 & 4.0 & 1.40 & .04 \\
Educational value of & $(.65)$ & $(.52)$ & $(.63)$ & & \\
Alien Rescue & & & & & \\
\hline
\end{tabular}

Note: $N=66$ for all subscales

*Significant at the .05 level; **significant at the .01 level.

\section{DISCUSSION}

This study shows that the cognitive modeling version of the hypermedia based expert tool offered more effective support than either of the other two versions. Its impact on learners can be seen in their actions within the environment, in the solutions they developed, and in their attitude toward the expert tool.

Several patterns within the self-directed study data suggest ways in which the expert modeling affected how students worked within the PBL unit. First, the modeling impacted learners' use of the tools within the hypermedia program, with learners in the modeling condition using tools in a manner that was more consistent with the expert's use of those tools than did students in the other two conditions. They were more likely to organize their notes into sections, accessed the notebook far more frequently, and consulted their probe mission statements more often while designing probes. Watching the expert use these tools led students to use tools within the environment in a similar way. Since tool functionality was demonstrated for all of the treatment groups, these differences can only be attributed to the effect of the modeling.

Second, there is evidence that the modeling affected students' cognition, helping them to work more effectively than students in the other treatment conditions. Students in the modeling group designed significantly fewer probes, but were significantly more likely to write meaningful mission statements for their probes. The large effect size suggests that the modeling condition was quite 
effective in encouraging students to act in a more planful manner than their peers in other conditions.

This difference in cognition also appeared in the problem-solving data, with students in the modeling group again outperforming their peers in either of the other conditions. These results suggest that the cognitive modeling offered by the expert tool not only led students to apply effective problem-solving strategies to their work, it impacted the quality of their reasoning and their ability to present it in a convincing rationale for their solutions. In order to write an effective rationale, students had to have developed proficiency in handling a variety of tasks throughout their work in the PBL unit and had to organize the information they gleaned in a meaningful way. In this way, the more effective self-directed study that resulted from the expert modeling led to better problem solving.

Of particular interest was the performance of the learners in the didactic condition. These learners received the same advice from the expert as learners in the cognitive modeling condition. Yet their actions during periods of self-directed study were far less likely to resemble those of the expert than were the actions of their peers in the modeling group. In fact, their actions did not differ significantly (with one exception, as discussed below) from those of learners in the help group, even though the help group received no advice from the expert on how to work effectively. In terms of problem solving, again students in the didactic condition did no better than students in the help condition. These results suggest that simply providing tips and examples is insufficient to impact learners' actions or understanding; students do not apply advice and examples offered by an expert unless they see them modeled on activities similar to the ones in which they are engaged.

Taken together, these results show that the cognitive modeling offered by the expert tool used in this study supports students in working more competently during PBL. Comparison of the modeling condition with the help condition shows that the addition of expert support during PBL can help students to work effectively. Comparison of the modeling condition with the didactic condition suggests that it is the modeling of expert strategies, rather than the mere presentation of them, which impacts students' work.

One anomaly appeared in the self-directed study data that cannot be explained by the impact of the expert tool, but which may suggest a need for future study. Students in the help condition exhibited some behaviors that more closely resembled those of the expert than students in the didactic condition. In one measure, the use of lists in the notebook, the difference between the help and didactic groups was statistically significant. Some of the descriptive data also shows unexpected differences between the didactic and help groups. The help group took more notes than did the didactic group. The help group also had fewer students who took no notes: while all but one student in the modeling condition and two students in the help condition recorded notes, seven students in the didactic condition failed to use the notebook. Informal classroom observations suggest that students in the help condition tended to interact more with their peers 
than students in the other two conditions, and that they tended to model some helpful activities for each other, particularly in note taking. This difference may therefore be the result of peer modeling, though additional research would be needed to test this hypothesis.

Contrary to the concern raised in the review of literature, this study found no evidence that modeling undermines students' attitudes toward PBL. The results of the Attitude Toward Learning environment questionnaire showed that students in the modeling condition enjoyed Alien Rescue just as much as students in the other conditions. It further showed students in the modeling condition liked the expert better and thought the expert tool was more helpful than did students in the other two conditions. These results suggest that rather than feeling that the expert undermines their control over their activities during self-directed study, students may actually like the tool because they feel that it offers effective support.

Unlike most studies that have examined programs employing modeling, this study was designed to isolate the effects of the modeling from other aspects of the instructional approach, such as opportunity for practice or access to expert suggestions. As a result, it is possible to attribute the differences between groups to the effects of modeling rather than to the approach as a whole. The findings of this study are consistent with those of Schunk, who found that cognitive modeling of an expert's strategies was more effective than didactic instruction in promoting accuracy in solving division problems [17].

These findings have several implications for problem-based learning and hypermedia.

\section{Implications for Problem-Based Learning}

The findings of this study indicate strong support for the inclusion of expert modeling during PBL, at least for the population studied here, who, as the literature on PBL suggests, may lack the skills traditionally considered prerequisite for PBL. The modeling impacted the way students worked during self-directed study, bringing their actions more into line with the way an expert approached the problem. This in turn led to more well developed solutions to the problem.

A concern was raised in the review of literature that modeling may undermine students' sense of autonomy and control over their activities during PBL if students believe that they must model their actions on those of the expert. This could in turn erode the positive attitude students normally report for PBL. However, the results of this study suggest that this was not the case here. Students in the modeling condition expressed similarly positive attitudes toward the PBL environment and a better attitude toward the expert than students in the other conditions. This study therefore showed that, through the provision of an expert cognitive modeling tool, it is possible to support students' development of problem-solving skills without undermining their attitude toward PBL. 
There is also resounding evidence for the effectiveness of PBL with regular education students of middle school age. Regardless of treatment condition, students stayed focused on a complex problem for three weeks, conducting research to gather the information they needed, sharing their findings with their classmates, and critiquing each other's solution plans. Students showed evidence of complex problem-solving strategies. Such results warrant continued efforts in finding ways to make PBL a viable approach for a wide range of learners.

\section{Implications for Hypermedia}

The results of this study show that hypermedia can provide cognitive apprenticeship-style support, making it possible to share with the classroom teacher the task of scaffolding students' work in complex learning environments. The non-linear, interactive format of hypermedia means that support can be offered "just-in-time" and under learner control. Providing this type of support would be overwhelming for a classroom teacher, making it unlikely that PBL would be used extensively without hypermedia support, especially with the types of learners who participated in this study. Through the provision of cognitive tools such as the one under investigation in this study, hypermedia can make challenging approaches like PBL viable for a wide range of learners and teachers.

In terms of the design of this expert tool, an important distinction must be drawn between two conceptions of the role of technology in education. Early in its development, the computer was used as a teacher, presenting information, asking questions, and judging responses. Recently there has been a shift to a view of technology as a collection of cognitive tools, the purpose of which is to support and extend the thinking processes of learners. This enables learners to engage in challenging tasks that would normally be overwhelming, and construct a more profound understanding than they would otherwise. Jonassen, Peck, and Wilson point out that in that early technology-as-teacher paradigm, both students and computers were expected to perform tasks better filled by the other [18]. Students were expected to receive, store, and retrieve information, something computers do well, while computers were expected to make decisions about learning, a task best left to humans. The result was inert knowledge and passive learners. One of the reasons the tool under investigation successfully supported learning within a PBL environment may be that it was not designed to make decisions or judgments about students' actions. It left those tasks to the students themselves. Rather, it offered them an expert model of productive actions but left them free to perform as they deemed best. Had the expert tool been designed to be "intelligent" enough to respond to students' actions, it may have interfered with learner ownership of the problem-solving process. In this light, an essential feature of the expert tool is that it function as a cognitive tool, under learner control, extending learners' thinking processes without controlling how they participate in complex learning environments. 
Computer-based cognitive apprenticeship style support is normally seen as the domain of intelligent tutoring systems (ITSs), which can diagnose learners' actions and provide coaching. The success of the expert tool examined in this study suggests that cognitive apprenticeship can also inform the design of some reasonably "low-tech" tools that may be more appropriate in some situations than high-powered ITSs. Rather than investing in costly ITSs, inexpensive alternatives may be effective in scaffolding students' learning, especially for novices where coaching is not the most effective type of support or for situations where learner ownership of the process is of paramount importance.

The effectiveness of this tool in a PBL environment suggests that it may be capable of facilitating other challenging instructional approaches, though further examination is necessary to determine the appropriate conditions for its use. PBL may differ from other approaches in that, while offering students choices within a complex environment, it presents a limited environment with a limited number of useful activities. That is, it is possible to determine beforehand the types of activities students will need to engage in to solve the problem, and to develop support for those activities. The broader the range of possible student actions, the more general the supports would have to become in order to remain relevant. The strategies modeled by the expert in this study were highly relevant to a very specific problem; because they were immediately useful and understandable within the narrow context of the problem, they may have been more meaningful than general strategies modeled within a broad context.

\section{FURTHER RESEARCH}

This study focused on the use of PBL with regular education middle school students. The tool investigated here was designed to offer enough support so as to make PBL a viable approach for this population. Because PBL has already been shown to be beneficial for some learners, namely mature learners and the gifted, further research would be necessary before recommending changes to this approach for these learners. A scaffold like the expert tool may actually oversimplify the problem situation, reducing the challenge to a point that undermines the effectiveness of PBL for mature and/or gifted audiences.

This study examined the impact of the expert tool on individual performance. But individual performance provides only a partial understanding of the effects of a scaffold within a setting where collaboration is encouraged. A central focus of the constructivist framework that drives the current interest in PBL is that cognition and expertise are distributed across individuals and tools working together within a context, and that learning is an act of enculturation into a community's practices. Further research is needed to begin to understand the ways in which tools such as the one examined here impact groups of learners working together to accomplish the tasks of a community. The anomaly seen in the results on self-directed study, in which peer modeling may have accounted for the greater 
use of expert strategies by the help group than the didactic group, suggests the importance of the interactions of learners within the environment created by this PBL unit. One of the most powerful effects of a scaffold such as the expert tool may lie in its potential to impact a few students, who then impact the performance of the entire group. To gain a deeper understanding of the effects of cognitive tools, it is necessary to consider both the individual and the group as appropriate units of analysis.

\section{APPENDIX Attitude toward the Learning Environment Questionnaire}

1. The Alien Rescue computer program is interesting.

2. I think I took better notes after listening to the expert.

3. I didn't learn any science by working on Alien Rescue.

4. Time passed quickly while I was working on Alien Rescue.

5. I liked listening to the expert

6. Alien Rescue didn't help me to learn anything about the solar system.

7. I learned a lot about scientific instruments by using Alien Rescue.

8. I found Alien Rescue boring.

9. I wished the expert would talk less.

10. The expert didn't change the way I worked on the problem.

11. It was interesting to hear what the expert had to say about this problem.

\section{Disagree}

Strongly
Agree

Disagree Neutral Agree Strongly 
MODELING EXPERT COGNITIVE STRATEGIES / 379

12. Alien Rescue gave me a chance to $\quad \begin{array}{llllll}1 & 2 & 3 & 4 & 5\end{array}$ do the same types of things real scientists do.

13. Listening to the expert helped me to design better probes.

14. The expert was not very helpful.

15. The expert was bossy.

16. This problem would be a lot harder if there were no experts to give advice.

17. I think I would learn more science by using programs like Alien Rescue than I do in my regular science classes.

18. I would recommend this computer program (Alien Rescue) to my friends.

19. I would have liked to hear more from the expert.

$\begin{array}{lllll}1 & 2 & 3 & 4 & 5 \\ 1 & 2 & 3 & 4 & 5 \\ 1 & 2 & 3 & 4 & 5 \\ 1 & 2 & 3 & 4 & 5\end{array}$

$\begin{array}{lllll}1 & 2 & 3 & 4 & 5\end{array}$

$\begin{array}{lllll}1 & 2 & 3 & 4 & 5\end{array}$

\section{REFERENCES}

1. J. R. Savery and T. M. Duffy, Problem Based Learning: An Instructional Model and Its Constructivist Framework, Educational Technology, 35, pp. 31-38, 1995.

2. P. Blumberg and J. A. Michael, The Development of Self-Directed Learning Behavior in a Partially Teacher-Centered Problem-Based Learning Curriculum, Teaching and Learning Medicine, 4, pp. 3-8, 1991.

3. S. M. Williams, Putting Case Based Learning into Context: Examples from Legal, Business, and Medical Education, Journal of the Learning Sciences, 2, pp. 367-427, 1993.

4. S. A. Gallagher, W. J. Stepien, and H. Rosenthal, The Effects of Problem-Based Learning on Problem Solving, Gifted Child Quarterly, 36, pp. 195-200, 1992.

5. M. A. Albanese and S. Mitchell, Problem-Based Learning: A Review of Literature on its Outcomes and Implementation Issues, Academic Medicine, 68, pp. 52-81, 1993.

6. C. E. Hmelo and M. Ferrari, The Problem-Based Learning Tutorial: Cultivating Higher Order Thinking Skills, Journal for the Education of the Gifted, 20, pp. 401-422, 1997. 
7. T. Koschmann, A. C. Kelson, P. J. Feltovich, and H. S. Barrows, Computer-Supported Problem-Based Learning: A Principled Approach to the Use of Computers in Collaborative Learning, in CSCL: Theory and Practice of an Emerging Paradigm, T. Koschmann (ed.), Lawrence Erlbaum Associates, Inc., Mahwah, New Jersey, pp. 83-124, 1996.

8. W. J. Stepien, S. A. Gallagher, and D. Workman, Problem-Based Learning for Traditional and Interdisciplinary Classrooms, Journal for the Education of the Gifted, 16, pp. 338-357, 1993.

9. H. S. Barrows, A Taxonomy of Problem-Based Learning Methods, Medical Education, 20, pp. 481-486, 1986.

10. A. Collins, J. S. Brown, and S. E. Newman, Cognitive Apprenticeship: Teaching the Crafts of Reading, Writing, and Mathematics, in Knowing, Learning and Instruction: Essays in Honor of Robert Glaser, L. B. Resnick (ed.), Lawrence Erlbaum Associates, Hillsdale, New Jersey, pp. 453-494, 1989.

11. A. L. Brown, Metacognition, Executive Control, Self-Regulation, and Other More Mysterious Mechanisms, in Metacognition, Motivation, and Understanding, F. Weinert and R. Klewe (eds.), Lawrence Erlbaum Associates, Hillsdale, New Jersey, 1987.

12. S. Derry and A. Lesgold, Toward a Situated Social Practice Model for Instructional Design, in Handbook of Educational Psychology, D. C. Berliner and R. C. Calfee (eds.), Macmillan Library Reference, New York, pp. 787-806, 1996.

13. A. Collins, Cognitive Apprenticeship and Instructional Technology, in Educational Values and Cognitive Instruction: Implications for Reform, L. Idol and B. F. Jones (eds.), Lawrence Erlbaum Associates, Hillsdale, New Jersey, pp. 119-136, 1991.

14. L. Gugerty, Non-Diagnostic Intelligent Tutoring Systems: Teaching Without Student Models, Instructional Science, 25, pp. 409-432, 1997.

15. S. M. Williams, Anchored Simulations: Merging the Strengths of Formal and I Informal Reasoning in a Computer-Based Learning Environment, doctoral dissertation, Peabody College of Vanderbilt University, 1994.

16. D. C. Williams, The Effect of Expert Stories on Sixth Grade Students' Achievement and Problem Solving in Hypermedia Supported Authentic Learning Environments, Ed-Media World Conference on Educational Multimedia and Hypermedia, Seattle, Washington, pp. 112-118, 1999.

17. D. H. Schunk, Modeling and Attributional Effects on Children's Achievement: A Self-Efficacy Analysis, Journal of Educational Psychology, 73, pp. 93-105, 1981.

18. D. H. Jonassen, K. L. Peck, and B. G. Wilson, Learning with Technology: A Constructivist Perspective, Prentice Hall, Inc., Upper Saddle River, New Jersey, 1999.

Direct reprint requests to:

Susan Pedersen

Assistant Professor

Texas A\&M University

Department of Educational Psychology

4225 TAMU

College State, TX 77843-4225 